\title{
Anxiety among patients with diabetes mellitus evaluated using generalized anxiety disorder 7-item scale
}

\author{
Amit Thour, Ramninder Nagra, Arunjeet Gosal, Tejasav Sehrawat, Subhash Das ${ }^{1}$, Yashdeep Gupta \\ Departments of Medicine and 'Psychiatry, Government Medical College and Hospital, Chandigarh, India
}

\section{A B S T R A C T}

Background: Anxiety has been shown to be associated with poor outcomes in people with diabetes. However, there has been limited data, especially from India, which has specifically examined whether diabetes mellitus is associated with an increased likelihood of comorbid anxiety. Aim: The aim was to estimate the prevalence of anxiety in patients with diabetes and to determine the association of anxiety with age, sex, and other related parameters. Setting: Endocrine clinic, tertiary care hospital. Design: Cross-sectional. Materials and Methods: The study was cross-sectional carried out in endocrinology clinic of tertiary care hospital in North India. Cases were patients with type 2 diabetes mellitus above 30 years of age. Anxiety was assessed using the generalized anxiety disorders 7 -item (GADs-7) scale.The relationship with a sociodemographic profile, duration of diabetes, hypertension, and microvascular complications was also analyzed. Results: Seventy-three subjects (42.5\% females) with mean age $50.8 \pm 9.2$ years were evaluated. The prevalence of anxiety was $34 \%$. Severe anxiety (GAD-7 score $\geq 15$ ) was present in three (4\%) subjects, moderate anxiety (GAD-7 score $\geq 10$ ) was present in six $(8 \%)$ subjects, and mild anxiety was present in $16(22 \%)$ of subjects.Anxiety increased with fasting plasma glucose, hypertension, was more in women, but the differences were not statistically significant. Conclusions: Our study demonstrates a higher prevalence of anxiety in patients with type 2 diabetes. No factor was significantly associated with anxiety. Therefore, anxiety should be assessed in each and every patient, irrespective of other factors.

Key words: Diabetes mellitus, generalized anxiety disorders, generalized anxiety disorders-7, prevalence

\section{INTRODUCTION}

The prevalence of type 2 diabetes has rapidly increased globally. India ranks at number 2 in terms of an absolute number of people affected by diabetes. ${ }^{[1]}$ Sixty-five million people had diabetes by 2013, in India. The number of people with diabetes in India has been projected to increase to 109 million by $2035 .{ }^{[1]}$ Diabetes is associated with an increased risk of both physical and

\begin{tabular}{|l|l|}
\hline \multicolumn{2}{|c|}{ Access this article online } \\
\hline Quick Response Code: & Website: \\
\hline & www.joshd.net \\
\hline & \\
\hline
\end{tabular}

psychological complications, both of which impact on mortality. ${ }^{[2]}$ Depression and anxiety are highly prevalent psychological disorders in the general population. Though depression is the most investigated psychological disorder associated with diabetes, there has been little research conducted on the association of diabetes with anxiety. ${ }^{[3]}$

\begin{abstract}
This is an open access article distributed under the terms of the Creative Commons Attribution-NonCommercial-ShareAlike 3.0 License, which allows others to remix, tweak, and build upon the work non-commercially, as long as the author is credited and the new creations are licensed under the identical terms.
\end{abstract}

For reprints contact: reprints@medknow.com

How to cite this article: Thour A, Nagra R, Gosal A, Sehrawat T, Das $S$, Gupta Y. Anxiety among patients with diabetes mellitus evaluated using generalized anxiety disorder 7-item scale. J Soc Health Diabetes 2016;4:133-6.

Corresponding Author: Dr. Yashdeep Gupta, Department of Medicine, Government Medical College and Hospital, Sector 32, Chandigarh - 160 030, India. E-mail: dryashdeepgupta@gmail.com 
This study adds to the limited available information on the association between anxiety and diabetes, from India. ${ }^{[4,5]}$ To the best of our knowledge, the utility of generalized anxiety disorders 7-item (GAD-7) scale has been evaluated for the first time in India to study this association. ${ }^{[4,5]}$

\section{MATERIALS AND MethodS}

This cross-sectional study was carried out in September 2014 at the Government Medical College and Hospital, Chandigarh, India. This is a tertiary care hospital serving patients from both urban and rural areas. The patients with a diagnosis of type 2 diabetes above age 30 years were recruited on the voluntarily basis for this study. The GAD7 scale was used for evaluation of anxiety, and relevant clinical details were obtained. No intervention was part of the study and the investigations that were available with the patient were used for analysis purpose. The cases were not receiving any psychiatric treatment which could have an effect on the result.

\section{Generalized anxiety disorder 7-item scale}

Anxiety was assessed by administering the GAD-7 scale. This scale is useful for evaluating the presence and severity of GAD in clinical practice. This tool has several advantages. ${ }^{[6]}$ First, a 7-item anxiety scale - the GAD-7 - is a useful tool with strong criterion validity for identifying probable cases of GAD. Second, the scale is also an excellent severity measure as increasing scores on the GAD-7 are strongly associated with multiple domains of functional impairment and disability days. Third, although many patients had anxiety and depressive symptoms, factor analysis confirms GAD and depression as distinct dimensions, GAD-7 measuring GAD with high sensitivity and specificity with appropriate cut-offs. It assesses the symptoms experienced by participants during the 2-week period before they take the survey. On the basis of participant response to the frequency of any particular symptom $(0=$ not at all, $1=$ several days, $2=$ more than half of the days, and $3=$ nearly every day), a total score ranging from 0 to 21 was obtained, with higher scores indicating patients' increased self-report of anxiety severity. The division of GAD-7 scores into ratings of mild (5-9), moderate (10-14), and severe anxiety $(215)$ was used in this study. ${ }^{[6]}$ Those who had moderate to severe anxiety based on cut-off points in GAD-7 $\geq 10$ were referred to Psychiatry Department for further management. This cut point identifies patients with GAD with a sensitivity of $89 \%$ and specificity of $82 \%$.

\section{Clinical details}

The variables included in the study were sociodemographic factors, the presence of hypertension, and microvascular complications were also assessed. Since most of the patients were recruited as first-timers attending the endocrine clinic of the hospital, glycated hemoglobin (HbA1c) was not available for all patients. The analysis is, therefore, with recent fasting blood glucose (FBG) value (within the last 7 days), which was available for all patients. Moreover, the value of FBG is more easily understood by the patient, rather than an interpretation of HbA1c.

\section{Statistical analysis}

Numerical data are presented as a mean \pm standard deviation or percentages. Differences in characteristics between participants were tested with unpaired $t$-test for normally distributed variables, with the Wilcoxon rank sum test for skewed variables, and with the Chi-square test or Fisher exact test for categorical variables. The significance level was set at 5\%. All statistical analyses were carried out using Statistical Package for Social Sciences (SPSS Version 20.0, Chicago, IL, USA). A sample size of 73 was as per convenience. This sample size gave us the power of $90 \%$ with an alpha error of $10 \%$.

\section{RESULTS}

\section{Baseline characteristics}

We report data from 73 subjects. The mean age of the study population was $50.8 \pm 9.2$ years. About $42.5 \%$ of the subjects were males and $61.6 \%$ were from the urban area. Sixty percent of them had coexistent hypertension. About $45 \%$ had at least one microvascular (retinopathy, nephropathy, and neuropathy) complication. The mean duration of diabetes was $6.3 \pm 6.3$ years. Nearly, $50 \%$ of the subjects had moderate to severe hyperglycemia as indicated by fasting plasma glucose values $>150 \mathrm{mg} \%$.

Prevalence and characteristics of subjects with anxiety Anxiety as defined by GAD-7 score $\geq 5$ was present in $34 \%$ of the individuals. Severe anxiety (GAD-7 score $\geq 15$ ) was present in three (4\%) subjects, moderate anxiety (GAD-7 score 210 ) was present in six $(8 \%)$ subjects, and mild anxiety was present in $16(22 \%)$ of subjects. Anxiety was more prevalent in rural subjects as compared to urban ones. Women, subjects with hypertension, microvascular complications, and subjects with moderate to severe hyperglycemia had more anxiety [Table 1]. The differences were, however, nonsignificant. GAD-7 scores positively correlated only with fasting plasma glucose. The correlation was statistically nonsignificant [Table 2].

\section{Risk factor analysis}

In bivariate risk factor analysis [Table 3], men had 28\% fewer chances of anxiety than women. The presence of hypertension was associated with $29 \%$ more risk of having 


\begin{tabular}{|c|c|c|c|c|c|}
\hline \multirow[t]{2}{*}{ Variable } & \multirow{2}{*}{$\begin{array}{l}\text { Number of } \\
\text { subjects }\end{array}$} & \multirow{2}{*}{$\begin{array}{l}\text { Mean } \pm \text { SD/ } \\
\text { percentage }\end{array}$} & \multicolumn{2}{|c|}{ GAD } & \multirow[t]{2}{*}{$P$} \\
\hline & & & Normal $(n=48)(\%)$ & Anxiety $(n=25)(\%)$ & \\
\hline Age (years) & 73 & $50.8 \pm 9.2$ & $51.8 \pm 9.1$ & $48.9 \pm 9.5$ & 0.20 \\
\hline Duration of diabetes (years) & 73 & $6.3 \pm 6.3$ & $6.7 \pm 6.8$ & $5.6 \pm 5.3$ & 0.49 \\
\hline \multicolumn{6}{|l|}{ Sex } \\
\hline Women & 42 & 57.5 & $26(61.9)$ & $16(38.1)$ & \multirow[t]{2}{*}{0.46} \\
\hline Men & 31 & 42.5 & $22(71.0)$ & $09(29.0)$ & \\
\hline \multicolumn{6}{|l|}{ Place of residence } \\
\hline Urban & 45 & 61.6 & 30 (66.7) & 15 (33.3) & \multirow[t]{2}{*}{1.00} \\
\hline Rural & 28 & 38.4 & $18(64.3)$ & $10(35.7)$ & \\
\hline \multicolumn{6}{|l|}{ Hypertension } \\
\hline Yes & 44 & 60.3 & $28(63.6)$ & $16(36.4)$ & \multirow[t]{2}{*}{0.80} \\
\hline No & 29 & 39.7 & $20(69.0)$ & 09 (31.0) & \\
\hline \multicolumn{6}{|c|}{ Any microvascular complication } \\
\hline Yes & 39 & 53.4 & $25(64.1)$ & $14(35.9)$ & \multirow[t]{2}{*}{0.81} \\
\hline No & 34 & 46.6 & $23(67.6)$ & $11(32.4)$ & \\
\hline \multicolumn{6}{|l|}{ Fasting plasma glucose (mg \%) } \\
\hline$\leq 150$ & 33 & 45.8 & $24(72.7)$ & 09 (27.3) & \multirow[t]{2}{*}{0.45} \\
\hline$>150$ & 39 & 54.2 & $24(61.5)$ & $15(38.5)$ & \\
\hline
\end{tabular}

GAD: Generalized anxiety disorder, SD: Standard deviation

\begin{tabular}{lcc}
\hline $\begin{array}{l}\text { Table 2: Correlation of generalized anxiety disorder score } \\
\text { with continuous variables }\end{array}$ & Correlation coefficient & $\boldsymbol{P}$ \\
\hline Variable & -0.06 & 0.64 \\
\hline Age & 0.21 & 0.08 \\
Fasting plasma glucose & -0.01 & 0.93 \\
\hline Duration of diabetes &
\end{tabular}

\begin{tabular}{|c|c|c|c|c|}
\hline Variable & $n$ & $\begin{array}{c}\text { Subjects } \\
\text { with anxiety }\end{array}$ & $\begin{array}{l}\text { Bivariate OR } \\
(95 \% \mathrm{CI})\end{array}$ & $\boldsymbol{P}$ \\
\hline \multicolumn{5}{|l|}{ Sex } \\
\hline Women & 42 & 16 & 1.00 & 0.54 \\
\hline Men & 31 & 09 & $0.72(0.26-2.04)$ & \\
\hline \multicolumn{5}{|l|}{ Residence } \\
\hline Urban & 45 & 15 & 1.00 & 0.92 \\
\hline Rural & 28 & 10 & $1.06(0.35-3.16)$ & \\
\hline \multicolumn{5}{|c|}{ Complications } \\
\hline Yes & 39 & 14 & 1.00 & 0.97 \\
\hline No & 34 & 11 & $1.02(0.32-3.50)$ & \\
\hline \multicolumn{5}{|c|}{ Hypertension } \\
\hline No & 29 & 09 & 1.00 & 0.65 \\
\hline Yes & 44 & 16 & $1.29(0.44-3.74)$ & \\
\hline \multicolumn{5}{|c|}{$\begin{array}{l}\text { Fasting plasma glucose } \\
\text { (mg \%) }\end{array}$} \\
\hline$\leq 150$ & 33 & 09 & 1.00 & 0.73 \\
\hline$>150$ & 39 & 15 & $1.23(0.39-3.93)$ & \\
\hline \multicolumn{5}{|c|}{ Duration of diabetes (years) } \\
\hline$<3$ & 28 & 08 & 1.00 & 0.51 \\
\hline$\geq 3$ & 44 & 16 & $1.47(0.47-4.61)$ & \\
\hline \multicolumn{5}{|c|}{ Age (years) } \\
\hline$<50$ & 33 & 13 & 1.00 & 0.17 \\
\hline$\geq 50$ & 39 & 11 & $0.44(0.14-1.42)$ & \\
\hline
\end{tabular}

anxiety. The risk of anxiety was nearly same with presence or absence of microvascular complications. Subjects from urban or rural residence had nearly equal chances of having anxiety. Fasting plasma glucose $\leq 150 \mathrm{mg} \%$ was associated with $23 \%$ lesser risk for depression.

\section{DISCUSSION}

The main anxiety disorders associated with medical illness are GAD and panic disorder. ${ }^{[3]}$ This study evaluated the presence of GAD in patients with type 2 diabetes mellitus and found the prevalence of 34\% using a GAD-7 scale. Though the data from India is limited, ${ }^{[4,5]}$ similar results have been found in other populations. ${ }^{[4,7-9]}$ The metaanalysis also showed an excess risk of $48 \%$ for elevated anxiety symptoms in patients with diabetes as compared to those without diabetes. ${ }^{[3]}$

In our earlier study, we found high prevalence (41\%) of depression among patients with type 2 diabetes. ${ }^{[10]}$ A meta-analysis indicates that people with diabetes are 2-fold more likely to be diagnosed with depression as compared to people who do not have diabetes. ${ }^{[1]}$ This implies that psychological factors, such as depression and anxiety, are common symptoms in patients with diabetes. ${ }^{[3]}$ If social support can be strengthened in these patients, then psychological factors can be improved. A recent study assessed the benefits of an education program on diabetes, patient self-management, adherence to medication, anxiety, depression, and glycemic control in type 2 diabetics in Saudi Arabia and found positive results with this approach. ${ }^{[12]}$ Identification and treatment of anxiety disorder in patients with type 2 diabetes is important, as in people with diabetes co-morbid anxiety disorders and elevated anxiety symptoms have been shown to be associated with increased diabetes symptom burden, increased diabetes complications, increased pain, worsened blood glucose levels, reduced quality of life, increased depression, increased body-mass index, and greater disability. ${ }^{[3]}$ 
In our study, we found that patients with a higher fasting plasma glucose $(>150 \mathrm{mg} / \mathrm{dl})$ had a higher prevalence of anxiety $(38.5 \%)$ than those with fasting plasma glucose $(<150 \mathrm{mg} / \mathrm{dl})(27.3 \%)$. This may be due to fear in the patient regarding the efficacy of his/her treatment regimen or fear of developing complications. The relationship may be bi-directional. Worse glycemic control may be associated with higher anxiety scores, and high anxiety levels may deteriorate glycemic control. This lay emphasizes the need to take care of both aspects so that both outcomes and quality of life can be improved in these patients.

A large proportion of women were found to have GAD, as compared to men. The similar results have been reported by others. ${ }^{[4,13]}$ Lower literacy levels among women may be one of the factors, lack of social support may be other factor for this result. In general, women also have higher anxiety levels than men. We found no significant correlation with age and duration of diabetes. No significant difference was found with presence or absence of microvascular complications. This may imply the overall need for assessment for GAD irrespective of other factors.

The comorbid conditions of anxiety and depression may easily go unnoticed, especially in the tertiary care settings in developing countries like India due to the huge patient load on the physicians in busy outpatient departments. As these co-morbid conditions reduce the efficacy of the treatment regimens of diabetes and add an additional burden on the patient, it is highly imperative we diagnose and treat these conditions along with. It has been previously seen that if patients can get a better understanding of the correlation between their disease and psychosocial factors in addition to having access to social support, then they can more easily improve attitude toward the chronic illness. ${ }^{[12]}$

Our study has some limitations including the fact that the study was conducted in a tertiary hospital setting which may in itself mean higher anxiety levels in the participants. Another drawback is the limited sample size. Moreover, the causality relationship cannot be fully ascertained it being a cross-sectional study. Further studies with a larger sample may shed light on the issue.

\section{CONCLUSIONS}

The study clearly establishes a connection between anxiety disorders and diabetes. In this age of medicine where highly successful treatment modalities are present and the association between the two conditions is widely known, the detection of the psychological issues is highly important. The higher prevalence of anxiety in women portrays a gender gap which needs to be addressed. With increased severity of the disease, it becomes necessary for an endocrinologist to provide psychosocial relief to the patient. This may significantly improve the quality of life in a patient.

Financial support and sponsorship

Nil.

Conflicts of interest

There are no conflicts of interest.

\section{REFERENCES}

1. Guariguata L, Whiting DR, Hambleton I, Beagley J, Linnenkamp U, Shaw JE. Global estimates of diabetes prevalence for 2013 and projections for 2035. Diabetes Res Clin Pract 2014;103:137-49.

2. Lynch CP, Gebregziabher M, Zhao Y, Hunt KJ, Egede LE. Impact of medical and psychiatric multi-morbidity on mortality in diabetes: Emerging evidence. BMC Endocr Disord 2014;14:68.

3. Smith KJ, Béland M, Clyde M, Gariépy G, Pagé V, Badawi G, et al. Association of diabetes with anxiety: A systematic review and meta-analysis. J Psychosom Res 2013;74:89-99.

4. Chaudhry R, Mishra P, Mishra J, Parminder S, Mishra BP. Psychiatric morbidity among diabetic patients: A hospital-based study. Ind Psychiatry J 2010;19:47-9.

5. Balhara YP, Sagar R. Correlates of anxiety and depression among patients with type 2 diabetes mellitus. Indian J Endocrinol Metab 2011;15 Suppl 1:S50-4.

6. Spitzer RL, Kroenke K, Williams JB, Löwe B. A brief measure for assessing generalized anxiety disorder: The GAD-7. Arch Intern Med 2006;166:1092-7.

7. Kaur G, Tee GH, Ariaratnam S, Krishnapillai AS, China K. Depression, anxiety and stress symptoms among diabetics in Malaysia: A cross sectional study in an urban primary care setting. BMC Fam Pract 2013;14:69.

8. Wu SF, Young LS, Yeh FC, Jian YM, Cheng KC, Lee MC. Correlations among social support, depression, and anxiety in patients with type-2 diabetes. J Nurs Res 2013;21:129-38.

9. Tovilla-Zárate C, Juárez-Rojop I, Peralta Jimenez Y, Jiménez MA, Vázquez $\mathrm{S}$, Bermúdez-Ocaña $\mathrm{D}$, et al. Prevalence of anxiety and depression among outpatients with type 2 diabetes in the Mexican population. PLoS One 2012;7:e36887.

10. Thour A, Das S, Sehrawat T, Gupta Y. Depression among patients with diabetes mellitus in North India evaluated using patient health questionnaire-9. Indian J Endocrinol Metab 2015;19:252-5.

11. Anderson RJ, Freedland KE, Clouse RE, Lustman PJ. The prevalence of comorbid depression in adults with diabetes: A meta-analysis. Diabetes Care 2001;24:1069-78.

12. Al Hayek AA, Robert AA, Al Dawish MA, Zamzami MM, Sam AE, Alzaid AA. Impact of an education program on patient anxiety, depression, glycemic control, and adherence to self-care and medication in type 2 diabetes. J Family Community Med 2013;20:77-82.

13. Mikaliukštiene A, Žagminas K, Juozulynas A, Narkauskaite L, Salyga J, Jankauskiene K, et al. Prevalence and determinants of anxiety and depression symptoms in patients with type 2 diabetes in Lithuania. Med Sci Monit 2014;20:182-90. 